\title{
Refractive Outcomes of Table-Mounted and HandheldAuto-Refractometers in Children: An Observational Cross-Sectional Study
}

müjdat karabulut ( $\square$ mujdatkarabulut@gmail.com )

Mugla Sıtkı Koçman University Medical School, Department of Ophthalmology, Mugla, Turkey sinem karabulut

Mugla Sıtkı Koçman University Medical School, Department of Ophthalmology, Mugla, Turkey Aylin karalezli

Mugla Sıtkı Koçman University Medical School, Department of Ophthalmology, Mugla, Turkey

\section{Research Article}

Keywords: Autorefractors, cylindrical power, Jackson cross-cylinder, spherical equivalent spherical power

Posted Date: January 20th, 2021

DOI: https://doi.org/10.21203/rs.3.rs-148950/v1

License: (1) This work is licensed under a Creative Commons Attribution 4.0 International License.

Read Full License 


\section{Abstract}

Background: To compare the refractive results of two autorefractors.

Methods: We designed this study as an observational, cross-sectional study. We compared the mean spheric and cylinder power, spherical equivalent, Jackson cross-cylinder values, determined the limits of agreement (LoA), and evaluated reliability.

Results: Nidek HandyRef-K autorefractor measured more astigmatism and myopia in terms of the mean cylindrical power $(P<.001)$ and spherical equivalent $(P=.024)$. Nidek HandyRef-K showed significantly more myopic results in subgroups with spherical power more than +1.50 Diopters (D) hyperopia and -3.00 $\mathrm{D}$ myopia ( $P=.031 ; P=.045 ; P=.026$; respectively) and higher astigmatism in the subgroup with the cylindric power less than $-1.00 \mathrm{D}(P<.001)$. The mean differences and 95\% LoA were $0.06 \mathrm{D} \pm 0.47 \mathrm{D}$ $(-0.82 \mathrm{D}$ to $0.98 \mathrm{D})$ in spherical power, $0.08 \mathrm{D} \pm 0.28 \mathrm{D}(-0.47 \mathrm{D}$ to $0.64 \mathrm{D})$ in cylindrical power, $0.11 \mathrm{D} \pm$ $0.47 \mathrm{D}(-0.81 \mathrm{D}$ to $1.01 \mathrm{D})$ in spherical equivalent, $0.02 \mathrm{D} \pm 0.36 \mathrm{D}(-0.73 \mathrm{D}$ to $0.69 \mathrm{D})$ in Jackson crosscylinder power at $0^{\circ}, 0.005 \mathrm{D} \pm 0.54 \mathrm{D}(-1.07 \mathrm{D}$ to $1.06 \mathrm{D})$ in Jackson cross-cylinder power at $45^{\circ}$. There was a strong correlation for spherical power (Spearman's rho=0.99, $P<.001$ ), cylindrical power (Spearman's rho $=0.88, P<.001$ ), spherical equivalent (Spearman's rho $=0.98, P<.001$ ).

Conclusion: Nidek HandyRef-K showed more myopic results regarding spherical equivalent and cylindrical power. Nidek HandyRef-K showed significantly more myopia in spherical power more than +1.50 D hyperopia, -3.00 D myopia, and more prominent astigmatism in cylindrical power less than -1.00 D subgroups.

\section{Introduction}

Amblyopia is a treatable eye disease that occurs in early childhood and may result in irreversible vision loss if not detected and treated. Timely identification of refractive errors in children is crucial for visual development and preventing amblyopia. Although cycloplegic retinoscopy is the gold standard for evaluating refractive error in children, it has some limitations,[1] namely; it is time-consuming, requires an experienced retinoscopist, and may terminate the examination due to patient discomfort.

Different techniques, such as handheld auto-refractometers and photo refractometers, are commonly used to detect refractive errors [2]. The new generation table-mounted auto-refractometer is commonly used in ophthalmology clinics worldwide. Although these devices provide rapid and valid measurements of refractive error, they are bulky and not portable [3]. Table-mounted auto-refractometers are not useful for uncooperative and immobile patients.

On the other hand, handheld auto-refractometers are small, portable, and ergonomic and can be used anywhere as needed. They are also appropriate for newborns, infants, and bedridden patients or musculoskeletal abnormalities restricting their mobility. 
Cycloplegic refraction is essential for paralyzing accommodation and accurately measuring refractive error, especially in childhood. It can result in irritation, burning, light sensitivity, and blurred vision. However, these mild side effects are temporary and well-tolerated.

In this cross-sectional study, we compared the cycloplegic measurements of a table-mounted (Topcon TRK-2P; Topcon Medical Systems, Inc., Tokyo, Japan) and handheld (Nidek HandyRef-K; Nidek Co., Ltd., Tokyo, Japan) auto-refractometer, and determined the limits of agreement (LoA) and reliability of both devices.

\section{Methods}

Pediatric patients who visited the ophthalmology clinic for regular ocular examination were enrolled in this observational cross-sectional study. After informing the patients and their parents or legal representatives, consent was obtained from children, parents, or legal representatives. All patients underwent comprehensive ocular examination, including visual acuity, anteroposterior segments check, ocular motility, and the cover-uncover test. The exclusion criteria were patients with manifest strabismus or motility disorders; any type of nystagmus; a history of sensitivity to cyclopentolate; any type of media opacity; congenital or acquired corneal, lenticular, retinal, choroidal, or optic disc abnormalities; and participants who incorporated or had hypersensitivity reactions to cyclopentolate during the examination. Cyclopentolate 1\% (Cycloplegin; Abdi Ibrahim, Istanbul, Turkey) was applied three times at intervals of 5 min. Then patients waited for about $45 \mathrm{~min}$ to attain complete cycloplegia, which resulted in dilated pupils that did not react to intense light. The evaluation was performed in the same room and light condition, with Topcon TRK-2P and Nidek HandyRef-K by a single expert blinded to the study.

The standard refractometer model was used for both devices, and the mean spherical power $\left(\mathrm{S}_{\mathrm{pwr}}\right)$, cylindrical power $\left(\mathrm{C}_{\mathrm{pwr}}\right)$, and cylindrical axis $\left(\mathrm{C}_{\mathrm{ax}}\right)$ of three consecutive measurements were recorded using Statistical Package for the Social Sciences (SPSS) version 21.0.0.0 (IBM Corporation and other(s) $1989,2012)$. If three consecutive measurements from each device differed by more than $0.50 \mathrm{D}$, repeated evaluations were done until the variations decreased below $0.50 \mathrm{D}$.

In the SPSS program, spherical equivalent (SE), Jackson cross-cylinder power at $0^{\circ}\left(\mathrm{J}_{0}\right)$, and $45^{\circ}\left(\mathrm{J}_{45}\right)$ axis were computed using the following formulas: $\mathrm{SE}=\mathrm{S}_{\mathrm{pwr}}+\mathrm{C}_{\mathrm{pwr}} / 2 ; \mathrm{J}_{0}=-\left(\mathrm{C}_{\mathrm{pwr}} / 2\right) \cos 2 \mathrm{C}_{\mathrm{ax}} ;$ and $\mathrm{J}_{45}=-\left(\mathrm{C}_{\mathrm{pwr}} / 2\right)$ $\sin 2 \mathrm{C}_{\mathrm{ax}}$, respectively. Because the refractive errors of two eyes are correlated, measurements of the left eyes were analyzed.

All subjects were divided into subgroups according to the mean $\mathrm{S}_{\mathrm{pwr}}$ and $\mathrm{C}_{\mathrm{pwr}}$ of the Topcon TRK-2P values. The subgroups were designed considering the American Academy of Ophthalmology guidelines for correcting more than -3.00 D and +4.50 D isoametropia, -3.00 D and +1.50 D anisometropia, and $2.00 \mathrm{D}$ astigmatic refractive error in young children [4]. We also compared the mean astigmatic refractive error under $1.00 \mathrm{D}$ since it is mostly seen in clinical practice. 
After testing the normality and homogeneity of variables with the Shapiro-Wilk, Kolmogorov-Smirnov, and Levene's tests ( $p<0.05$ for all variables with all tests), the Wilcoxon signed-rank test was performed. The Bland-Altman plot was generated to determine the 95\% LoA. Spearman's rank correlation coefficient was used to assess reliability. $\mathrm{P}<0.05$ was respected as statistically significant.

The study was managed consistent with the Declaration of Helsinki's principle and approved by the Local Ethics Committee.

\section{Results}

The left eyes of 256 pediatric patients were evaluated in this study. The gender distribution was 127 females $(49 \%)$ and 129 males $(51 \%)$. The mean age ( \pm standard deviation [SD]) was $9.12 \pm 2.26$ years (range, 5-16 years). Figure 1 shows the age distribution.

There were no significant differences in $\mathrm{S}_{\mathrm{pwr}}, \mathrm{J}_{0}$, and $\mathrm{J}_{45}$ between the two devices $(P=.19, P=.56, P$ $=.247$, respectively; Table 1$)$. However, the Nidek HandyRef-K autorefractor measured more astigmatism and myopia in terms of mean $\mathrm{C}_{\mathrm{pwr}}(P<.001)$ and SE $(P=.024)$ and showed more prominent $\mathrm{C}_{\mathrm{ax}}(P=.037)$ compared to Topcon TRK-2P (Table 1).

Table 1

Comparison of the refractive measurement of two devices in all eyes.

\begin{tabular}{|c|c|c|c|}
\hline$S_{p w r}(D)$ Mean $\pm S D$ & Topcon TRK-2P & Nidek Handy Ref-K & P-value \\
\hline Range & $2.23 \pm 3.45$ & $2.17 \pm 3.39$ & \multirow[t]{2}{*}{0.191} \\
\hline$C_{p w r}(D)$ Mean $\pm S D$ & $(-4.50)-(15.25)$ & $(-4.75)-(14.75)$ & \\
\hline Range & $-0.75 \pm 0.83$ & $-0.84 \pm 0.85$ & \multirow[t]{2}{*}{$<0.001$} \\
\hline$C_{a x}\left({ }^{0}\right)$ Mean $\pm S D$ & $(-4.75)-(0.00)$ & $(-5.00)-(0.00)$ & \\
\hline \multirow{3}{*}{$\begin{array}{l}\text { Range } \\
\text { SE (D) Mean } \pm \text { SD }\end{array}$} & $82.84 \pm 72.94$ & $100.38 \pm 74.42$ & 0.037 \\
\hline & $0-180$ & $0-180$ & \\
\hline & $1.85 \pm 3.35$ & $1.75 \pm 3.30$ & \multirow[t]{2}{*}{0.024} \\
\hline \multirow{4}{*}{$\begin{array}{l}J_{0}(D) \text { Mean } \pm S D \\
\text { Range } \\
J_{45}(D) \text { Mean } \pm S D\end{array}$} & $(-4.88)-(14.88)$ & $(-5.25)-(14.50)$ & \\
\hline & $-0.08 \pm 0.36$ & $-0.06 \pm 0.36$ & \multirow[t]{2}{*}{0.560} \\
\hline & $(-1.99)-(1.80)$ & $(-1.57)-(1.90)$ & \\
\hline & $-0.05 \pm 0.42$ & $-0.04 \pm 0.47$ & \multirow[t]{2}{*}{0.247} \\
\hline Range & $(-2.16)-(1.54)$ & $(-1.92)-(2.40)$ & \\
\hline
\end{tabular}

$\mathrm{S}_{\mathrm{pwr}}$ : Spherical power, $\mathrm{C}_{\mathrm{pwr}}$ : Cylindrical power, $\mathrm{C}_{\mathrm{ax}}$ : Cylindrical axes, SE: Spherical equivalent, SD: Standard deviation, $\mathrm{D}$ : Diopter, $\mathrm{J}_{0}$ : Jackson cross-cylinder power at $0^{\circ}$ axis, $\mathrm{J}_{45}$ : Jackson cross-cylinder power at $45^{\circ}$ 
axis.

In subgroup analysis, Nidek HandyRef-K showed significantly more myopia in subgroups with $\mathrm{S}_{\mathrm{pwr}}$ between +1.50 D and +4.50 D hyperopia, more than $+4.50 \mathrm{D}$ hyperopia, and $-3.00 \mathrm{D}$ myopia $(P=.031, P$ $=.045, P=.026$, respectively; Table 2 ) compared to the Topcon TRK-2P.

Table 2

Comparison of the mean $S_{p w r}$ of two devices in the subgroups for $S_{p w r}$.

\begin{tabular}{|c|c|c|c|c|c|}
\hline \multirow[t]{2}{*}{ Subgroup for $S_{p w r}$} & Age (Year) & $\mathbf{N}$ & Topcon TRK-2P & Nidek Handy Ref-K & \multirow[t]{2}{*}{ P-value } \\
\hline & \multicolumn{2}{|l|}{ Mean (Range) } & \multicolumn{2}{|l|}{ Mean \pm SD } & \\
\hline$S_{p w r} \leq-3.00$ & $11.11(6-14)$ & 24 & $-4,19 \pm 0.77$ & $-4.40 \pm 0.90$ & 0.026 \\
\hline$-3.00<\mathrm{S}_{\mathrm{pwr}} \leq 0.00 \mathrm{D}$ & $7.98(5-15)$ & 76 & $-1.14 \pm 0.45$ & $-1,18 \pm 0.38$ & 0.541 \\
\hline $0.00 \leq S_{p w r}<+1.50 D$ & $8.22(5-16)$ & 54 & $0.62 \pm 0.53$ & $0.58 \pm 0.78$ & 0.305 \\
\hline$+1.50 \mathrm{D} \leq \mathrm{S}_{\mathrm{pwr}}<+4.50 \mathrm{D}$ & $7(5-13)$ & 61 & $2.01 \pm 1.02$ & $1.87 \pm 1.06$ & 0.031 \\
\hline$S_{p w r} \geq+4.50 D$ & $6.12(5-13)$ & 41 & $6.75 \pm 2.64$ & $6.51 \pm 2.61$ & 0.045 \\
\hline \multicolumn{6}{|c|}{$\mathrm{S}_{\mathrm{pwr}}:$ Spherical power, SD: Standard deviation, D: Diopter, N: Number } \\
\hline \multicolumn{6}{|c|}{$\begin{array}{l}\text { Nidek HandyRef-K also showed higher astigmatism and axes in the subgroup with } \mathrm{C}_{\mathrm{pwr}}<-1.00 \mathrm{D} \text { than } \\
\text { Topcon TRK-2P }(P<.001 \text { and } P=.025 \text {, respectively; Table } 3) \text {. }\end{array}$} \\
\hline
\end{tabular}


Table 3

Comparison of the mean $\mathrm{C}_{\mathrm{pwr}}$, axis, and Jackson cross-cylinder power in the subgroups for $\mathrm{C}_{\mathrm{pwr}}$.

\begin{tabular}{|c|c|c|c|c|c|}
\hline \multirow[t]{2}{*}{ Subgroup for $C_{p w r}$} & Age (Year) & $\mathbf{N}$ & Topcon TRK-2P & Nidek Handy Ref-K & \multirow[t]{2}{*}{ P-value } \\
\hline & Mean (Range) & & Mean \pm SD & & \\
\hline$C_{p w r} \leq-2.00$ & $6.2(5-13)$ & 64 & & & \\
\hline$C_{p w r}(D)$ & & & $-2.42 \pm 0.95$ & $-2.49 \pm 0.97$ & 0.245 \\
\hline$C_{a x}\left({ }^{0}\right)$ & & & $106.11 \pm 79$ & $130.37 \pm 68.52$ & 0.262 \\
\hline$J_{0}(D)$ & & & $-0.26 \pm 0.86$ & $-0.21 \pm 0.80$ & 0.831 \\
\hline $\mathrm{J}_{45}(\mathrm{D})$ & & & $-0.26 \pm 0.93$ & $0.03 \pm 1.1$ & 0.447 \\
\hline$-2.00<C_{p w r} \leq-1.00 D$ & $6.5(5-14)$ & 51 & & & \\
\hline$C_{p w r}(D)$ & & & $-1.13 \pm 0.13$ & $-1.05 \pm 0.34$ & 0.355 \\
\hline$C_{a x}\left({ }^{0}\right)$ & & & $76.19 \pm 76.71$ & $78.1 \pm 79.51$ & 0.134 \\
\hline $\mathrm{J}_{0}(\mathrm{D})$ & & & $-0.12 \pm 0.30$ & $-0.18 \pm 0.38$ & 0.709 \\
\hline $\mathrm{J}_{45}(\mathrm{D})$ & & & $0.03 \pm 0.48$ & $-0.12 \pm 0.36$ & 0.351 \\
\hline$-1.00 \mathrm{D}<\mathrm{C}_{\mathrm{pwr}}$ & $7.9(5-16)$ & 141 & & & \\
\hline$C_{p w r}(D)$ & & & $-0.38 \pm 0.25$ & $-0.52 \pm 0.34$ & $<0.001$ \\
\hline $\mathrm{C}_{\mathrm{ax}}\left({ }^{0}\right)$ & & & $79.22 \pm 71.11$ & $97.71 \pm 73.74$ & 0.025 \\
\hline$J_{0}(D)$ & & & $-0.04 \pm 0.15$ & $-0.02 \pm 0.18$ & 0.251 \\
\hline $\mathrm{J}_{45}(\mathrm{D})$ & & & $-0.02 \pm 0.17$ & $-0.05 \pm 0.24$ & 0.171 \\
\hline
\end{tabular}

$\mathrm{C}_{\mathrm{pwr}}$ : Cylindrical power, $\mathrm{C}_{\mathrm{ax}}$ : Cylindrical axes, SD: Standard deviation, D: Diopter, $\mathrm{J}_{0}$ : Jackson crosscylinder power at $0^{\circ}$ axis, $\mathrm{J}_{45}$ : Jackson cross-cylinder power at $45^{\circ}$ axis

The mean differences and 95\% LoA were 0.06 D $\pm 0.47 \mathrm{D}(-0.82 \mathrm{D}$ to $0.98 \mathrm{D})$ in $\mathrm{S}_{\text {pwr }}$ (Fig. 2), $0.08 \mathrm{D} \pm 0.28$ $D(-0.47 \mathrm{D}$ to $0.64 \mathrm{D})$ in $\mathrm{C}_{\text {pwr }}$ (Fig. 3), 0.11 D $\pm 0.47 \mathrm{D}$ (-0.81 D to $\left.1.01 \mathrm{D}\right)$ in SE (Fig. 4), $0.02 \mathrm{D} \pm 0.36 \mathrm{D}$ $(-0.73 \mathrm{D}$ to $0.69 \mathrm{D})$ in $\mathrm{J}_{0}$ (Fig. 5), $0.005 \mathrm{D} \pm 0.54 \mathrm{D}(-1.07 \mathrm{D}$ to $1.06 \mathrm{D})$ in $\mathrm{J}_{45}$ (Fig. 6).

There was a strong correlation for $\mathrm{S}_{\mathrm{pwr}}$ (Spearman's rho $\left.=.99, P<.001\right), \mathrm{C}_{\mathrm{pwr}}$ (Spearman's rho $=.88, P$ $<.001)$, SE (Spearman's rho $=.98, P<.001$ ); a moderate positive correlation for $J_{0}$ (Spearman's rho $=.32, P$ 
$<.001$ ); and a weak positive correlation for $J_{45}$ (Spearman's rho $=.17, P=.018$ ) between the two devices (Table 4).

Table 4

The reliability of two devices for $\mathrm{S}_{\mathrm{pwr}}, \mathrm{C}_{\mathrm{pwr}}, \mathrm{SE}, \mathrm{J}_{0}$, and $\mathrm{J}_{45}$ with the Spearman's correlation coefficient.

\begin{tabular}{|llllll|}
\hline & $\mathrm{S}_{\mathrm{pwr}}$ & $\mathrm{C}_{\mathrm{pwr}}$ & $\mathrm{SE}$ & $\mathrm{J}_{0}$ & $\mathrm{~J}_{45}$ \\
\hline Rho & 0.99 & 0.88 & 0.98 & 0.32 & 0.17 \\
\hline p-value & $<0.001$ & $<0.001$ & $<0.001$ & $<0.001$ & 0.018 \\
\hline
\end{tabular}

$\mathrm{S}_{\mathrm{pwr}}$ : Spherical power, $\mathrm{C}_{\mathrm{pwr}}$ : Cylindrical power, SE: Spherical equivalent, $\mathrm{J}_{0}$ : Jackson cross-cylinder power at $0^{\circ}$ axis, $\mathrm{J}_{45}$ : Jackson cross-cylinder power at $45^{\circ}$ axis, Rho: Spearman's rho

\section{Discussion}

The Nidek Handy Ref-K is a closed-field handheld, portable, easy-to-use, monocular auto-refractometer that detects refractive errors in infants, any age of childhood, and adolescents sitting, standing, or supine position. A fogging mechanism is exerted to reduce accommodation. Its measurement range is $-20.00 \mathrm{D}$ to $+20.00 \mathrm{D}$ sphere $(0.12 \mathrm{D} / 0.25 \mathrm{D}$ increments), cylinder $0 \mathrm{D}$ to $12.00 \mathrm{D}(0.12 \mathrm{D} / 0.25 \mathrm{D}$ increments), and axis $0^{\circ}$ to $180^{\circ}\left(1^{\circ} / 5^{\circ}\right.$ increments) [5].

Topcon TRK-2P is a table-mounted instrument that assembles a refractor keratometer, non-contact tonometer, and pachymeter in one compact device. However, these devices are large, difficult to move, and not appropriate for bedridden patients, infants, or any patient who cannot sit down to get measurements. The refractive measurement range of Topcon TRK-2P is - $30 \mathrm{D}$ to $+25 \mathrm{D}$ sphere $(0.12$ $\mathrm{D} / 0.25 \mathrm{D}$ increments), $0 \mathrm{D}$ to $12 \mathrm{D}$ cylinder $\left(0.12 \mathrm{D} / 0.25 \mathrm{D}\right.$ increments), and $0^{\circ}$ to $180^{\circ}\left(1^{\circ} / 5^{\circ}\right.$ increments) astigmatic axis.[6] Topcon TRK-2P also uses a fogging mechanism to diminish accommodation.

Screening the refractive error in childhood and adolescence without cycloplegia is controversial. Because accommodation is more active at these ages, it is challenging to estimate myopia's prevalence or latent hyperopia. The cycloplegic refraction is strongly recommended, especially in patients with strabismus or high refractive error $[7,8]$.

Cycloplegic agents have some side effects such as irritation, burning, photophobia. Some adverse reactions, such as concentration and memory problems, confusion, drowsiness, disorientation, and seizures, were reported $[9,10]$. However, these side effects are temporary and well-tolerated. Although some studies have shown that a handheld auto-refractometer is useful for non-cycloplegic screening for refractive errors, cycloplegic refraction is recommended to avoid problems caused by accommodation and to determine latent refractions in childhood and adolescence [11]. 
The accuracy of varied auto-refractometers differs concerning $\mathrm{S}_{\mathrm{pwr}}, \mathrm{C}_{\mathrm{pwr}}, \mathrm{SE}$, and $\mathrm{C}_{\mathrm{ax}}$, depending on cycloplegia. Mirzajani et al.[12] reported prominent variation in the $\mathrm{S}_{\mathrm{pwr}}, \mathrm{SE}$, and $\mathrm{J}_{45}$ vector between the Nidek table-mounted auto refractometer (Nidek ARK-510A; Gamagori, Japan) and Nidek ARK-30 handheld auto refractometer (NidekARK-30) in a multi-stage cluster sampling cross-sectional study. They found a strong positive correlation and fair agreement for $\mathrm{S}_{\mathrm{pwr}}, \mathrm{SE}, \mathrm{J}_{0}$, and $\mathrm{J}_{45}$ vectors. However, the patients' mean age was $32.7 \pm 18.72$ years, ranged from 3 to 90 years, and refractive measurements were undertaken in non-cycloplegic conditions with both devices.

Akil et al.[13] compared outcomes of a handheld (Retinomax K-plus 3; Righton, Tokyo, Japan) and a table-mounted (Canon RK-F1; Canon USA Inc., Lake Success, NY, USA) auto-refractometer. They evaluated significantly hyperopic results for mean SE with Canon RK-F1 before cycloplegia. Good agreement and no significant difference was obtained for $\mathrm{S}_{\mathrm{pwr}}, \mathrm{C}_{\mathrm{pwr}}, \mathrm{J}_{0}$, and $\mathrm{J}_{45}$ among Retinomax K-plus, Canon RK-F1, and cycloplegic retinoscopy after cycloplegia. However, their sample size was relatively small, and they did not compare the results in subgroups that were designed to measure $S_{p w r}$ and $C_{p w r}$.

In a cross-sectional study, Oral et al.[14] evaluated the cycloplegic results of a handheld autorefractor with cycloplegic retinoscopy and reported no significant difference in terms of mean $\mathrm{S}_{\mathrm{pwr}}, \mathrm{C}_{\mathrm{pwr}}$, and $\mathrm{SE}$, and a strong correlation with each other. Nevertheless, they also did not consider the results in subgroups that were designed for the $\mathrm{S}_{\mathrm{pwr}}$ and $\mathrm{C}_{\mathrm{pwr}}$.

Farook et al.[15] compared a handheld autorefractor (Retinomax K-plus 3; Righton, Tokyo, Japan) with a table-mounted autorefractor (Topcon RM8000B; Tokyo, Japan) and subjective refraction. They found that the Retinomax measured more myopia than the Topcon RM8000B and subjective refraction. However, their measurements were in non-cycloplegic condition and included adult participants.

Seymen et al.[16] compared three handheld autorefractors (HandyRef-K, Retinomax, and Plusoptix). They reported no significant difference among three handheld devices for mean $\mathrm{S}_{\mathrm{pwr}}$ and $\mathrm{C}_{\mathrm{ax}}$. However, the mean SE measured with Plusoptix was significantly more myopic compared to HandyRef-K and Retinomax. The authors also found that the mean $\mathrm{C}_{\mathrm{pwr}}$ measured by HandyRef- $\mathrm{K}$ was considerably higher compared to Plusoptix and Retinomax. In their study, refractive measurements with Plusoptix were undertaken in non-cycloplegic conditions, while those with HandyRef-K and Retinomax were in cycloplegic states. Moreover, they did not compare the mean $\mathrm{J}_{0}$ and $\mathrm{J}_{45}$ values.

This current study was designed as an observational cross-sectional study in pediatric patients whose ages ranged from 5 to 16 years in cycloplegic conditions. We found that the Nidek HandyRef-K handheld autorefractor measured more astigmatism and myopia in terms of mean $\mathrm{C}_{\mathrm{pwr}}, \mathrm{SE}$, and showed more prominent $\mathrm{C}_{\mathrm{ax}}$ compared to Topcon TRK-2P. Nidek HandyRef-K showed significantly myopic results in subgroups with $S_{p w r}$ between $+1.50 \mathrm{D}$ and $+4.50 \mathrm{D}$ hyperopia, more than $+4.50 \mathrm{D}$ hyperopia, and -3.00 D myopia. Nidek HandyRef-K also showed more prominent astigmatism and axes in the subgroup with $\mathrm{C}_{\mathrm{pwr}}$ less than $-1.00 \mathrm{D}$ compared to the Topcon TRK-2P. Clinically, there was a good agreement for $\mathrm{S}_{\mathrm{pw}}$, 
$\mathrm{C}_{\mathrm{pwr}}, \mathrm{SE}, \mathrm{J}_{0}$, and $\mathrm{J}_{45}$. There was also a strong correspondence for $\mathrm{S}_{\mathrm{pwr}}, \mathrm{C}_{\mathrm{pwr}}, \mathrm{SE}$; a moderate positive correlation for $\mathrm{J}_{0}$; and a weak positive correlation for $\mathrm{J}_{45}$ between two devices.

This study had some limitations. The primary flaw was not comparing the results with cycloplegic retinoscopy. We could not measure cycloplegic retinoscopy from all the patients due to technical problems with the device when the study continued. Therefore we did not reach enough cycloplegic retinoscopy results for the comparison. We also did not compare the repeatability of $\mathrm{S}_{\mathrm{pw}}$ and $\mathrm{C}_{\mathrm{pwr}}$ with both devices.

In conclusion, the two autorefractors showed clinically suitable agreement intervals and reliability for $\mathrm{S}_{\mathrm{pwr}}, \mathrm{C}_{\mathrm{pwr}}, \mathrm{SE}, \mathrm{J}_{0}$, and $\mathrm{J}_{45}$ in cycloplegic conditions, although Nidek HandyRef-K measured more astigmatism and myopia. Nidek HandyRef-K showed significantly myopic results in patients whose $\mathrm{S}_{\mathrm{pwr}}$ was more than $+1.50 \mathrm{D}$ hyperopia and $-3.00 \mathrm{D}$ myopia and more prominent astigmatism in patients whose $C_{p w r}$ was less than $-1.00 \mathrm{D}$ compared to Topcon TRK-2P. These differences should be kept in mind in clinical practice to correct the refractive error in pediatric age.

\section{Declarations}

Ethics approval and consent to participate: In this study's procedures, we followed the local institutional research committee's ethical standards and the 1964 Helsinki declaration of ethical standards. Informed consent was gathered from all individual participants and their parents. Muğla Sıtkı Koçman University Clinical Research Ethics Committee arranged ethical approval.

Consent for publication: Not applicable

Availability of data and materials: All data generated or analyzed during this study are included in this published article.

Competing interests: The authors have no financial or proprietary interest in a product, method, or material described herein.

Funding: This research did not take any specific grant from funding agencies in the public, commercial, or not-for-profit sectors.

Authors' contributions: Müjdat Karabulut, Sinem Karabulut, and Aylin Karalezli have made substantial contributions to conception and design, data acquisition, analysis, and interpretation of data. Müjdat Karabulut, Sinem Karabulut, and Aylin Karalezli have given final approval of the version to be published. All the authors agree to be accountable for all aspects of the work in ensuring that questions related to the accuracy or integrity of any part of the work are appropriately investigated and resolved.

Acknowledgments: Not applicable 


\section{References}

1. Schimitzek T, Haase W. Efficiency of a video-auto refractometer used as a screening device for amblyogenic factors. Graefes Arch Clin Exp Ophthalmol 2002;240(9):710-6.

2. Group PEDI. The clinical profile of moderate amblyopia in children younger than seven years. Arch Ophthalmol 2002;120(3):281-7.

3. Akil H, Keskin S, Çavdarli C. Comparison of the refractive measurements with handheld auto refractometer, table-mounted auto refractometer and cycloplegic retinoscopy in children. Korean $\mathrm{J}$ Ophthalmol 2015;29(3):178-184.

4. American Academy of Ophthalmology. Types of Amblyopia. 2015.

5. Handheld Ref/Keratometer / Handheld Refractometer NIDEK HandyRef-K Handheld Ref/Keratometer / Handheld Refractometer. 2015.

6. TRK-2P- Topcon. TRK-2P, Kerato-refractometer, tono-pachymeter. 2018.

7. Bujara K, Schulz E, Haase W. Retinoscopy under cycloplegic and non-cycloplegic conditions in children comparison of measurements of three examiners (author's transl). Graefes Arch Clin Exp Ophthalmol 1981;216(4):339-43.

8. Hiatt RL, Jerkins G. Comparison of atropine and tropicamide in esotropia. Ann Ophthalmol 1983;15(4):341-3.

9. Derinoz O, Er A. Inability to walk, disequilibrium, incoherent speech, disorientation following the instillation of 1\% cyclopentolate eye drops case report. Pediatr Emerg Care 2012;28(1):59-60.

10. Bryant SM, Rhee JW, Thompson TM, et al. Parenteral ophthalmic tropicamide or cyclopentolate protects rats from lethal organophosphate poisoning. Am J Ther 2009;16(3):231-4.

11. Cordonnier M, Kallay $\mathrm{O}$. Non-cycloplegic screening for refractive errors in children with the handheld autorefractor Retinomax: final results and comparison with non-cycloplegic photo screening Strabismus. 2001;9(2):59-70.

12. Mirzajani A, Qasemi F, Asharlous A, et al. Are the results of handheld auto-refractometer as valid as the result of table-mounted refractometer? J Curr Ophthalmol 2018;22;31(3):305-311.

13. Akil $\mathrm{H}$, Keskin S, Çavdarli C. Comparison of the refractive measurements with handheld auto refractometer, table-mounted auto refractometer and cycloplegic retinoscopy in children. Korean $\mathrm{J}$ Ophthalmol. 2015;29(3):178-84.

14. Oral Y, Gunaydin N, Ozgur O, et al. A comparison of different autorefractors with retinoscopy in children. J Pediatr Ophthalmol Strabismus 2012;49(6):370-7.

15. Farook M, Venkatramani J, Gazzard G, et al. Comparisons of the handheld autorefractor, tablemounted autorefractor, and subjective refraction in Singapore adults. Optom Vis Sci 2005;82(12):1066-70.

16. Seymen Z, Vural E, Eris E et al. HandyRef-K: Comparison of the latest handheld auto refractokeratometer with retinomax and plusoptix in patients younger than three years of age. Beyoglu Eye $J$ 2019; 4: 32-37. 
Figures

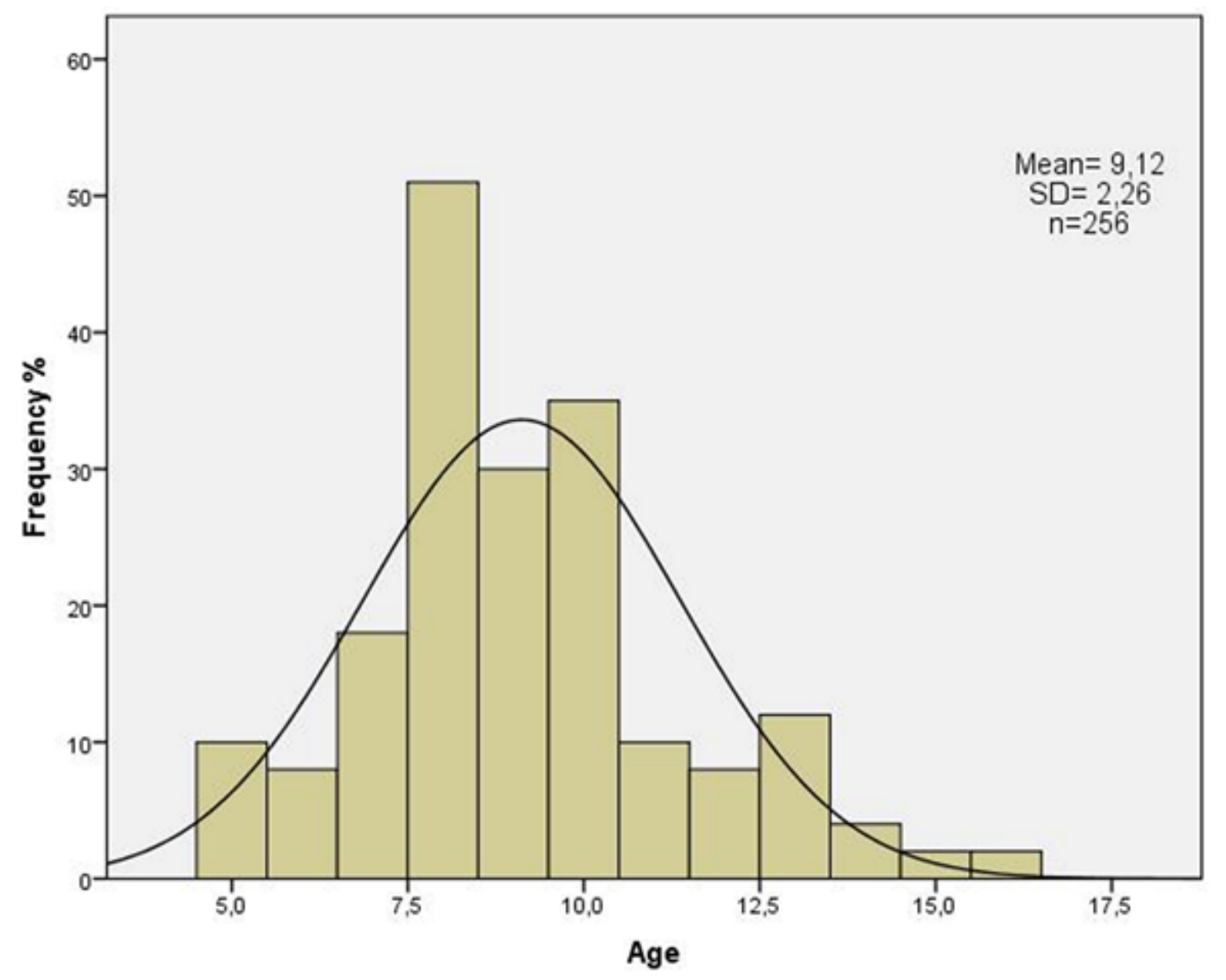

Figure 1

It demonstrates the age (year) disruption of 256 patients. 


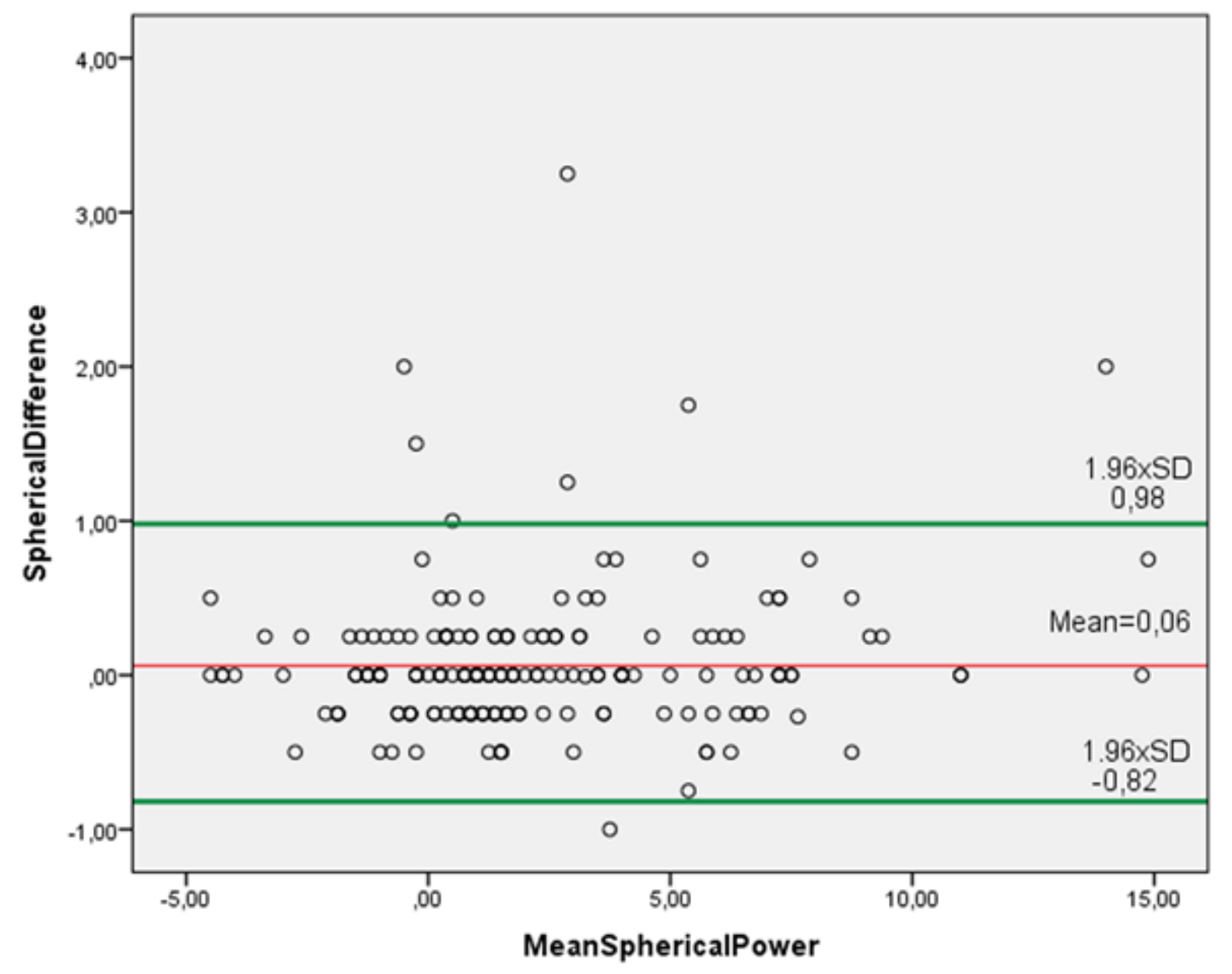

\section{Figure 2}

Bland Altman plot indicates the agreement between Topcon TRK-2P and Nidek HandyRef-K for the mean spherical power. The middle line demonstrates the mean difference of spherical power $(0.06 \mathrm{D} \pm 0.47 \mathrm{D})$, and the other two side lines show the $95 \%$ limits of agreement (-0.82 D to $0.98 \mathrm{D})$. 


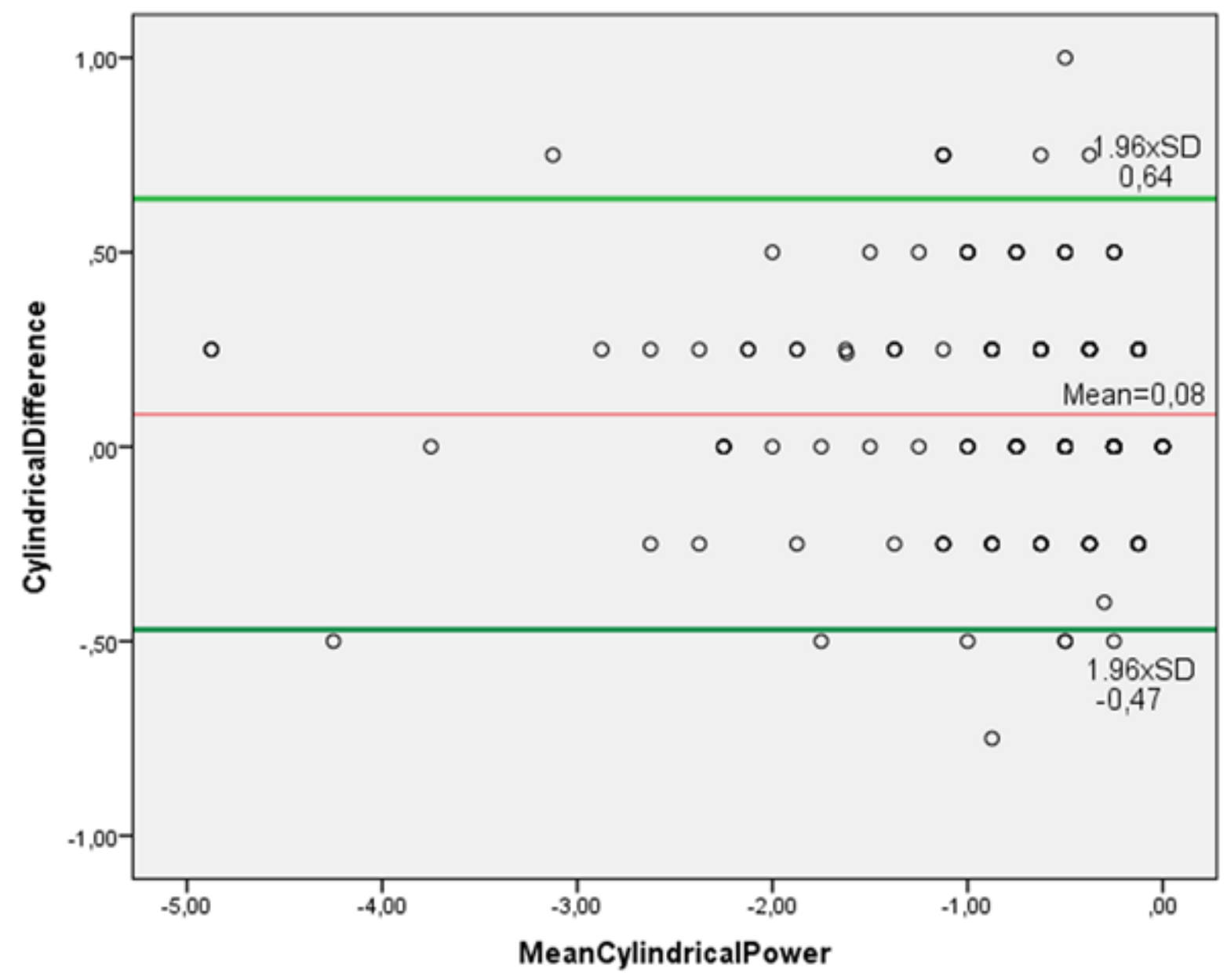

Figure 3

Bland Altman plot indicates the agreement between Topcon TRK-2P and Nidek HandyRef-K for the mean cylindrical power. The middle line demonstrates the mean difference (0.08 $D \pm 0.28 \mathrm{D})$, and the other two side lines show the $95 \%$ limits of agreement (-0.47 D to $0.64 \mathrm{D})$. 


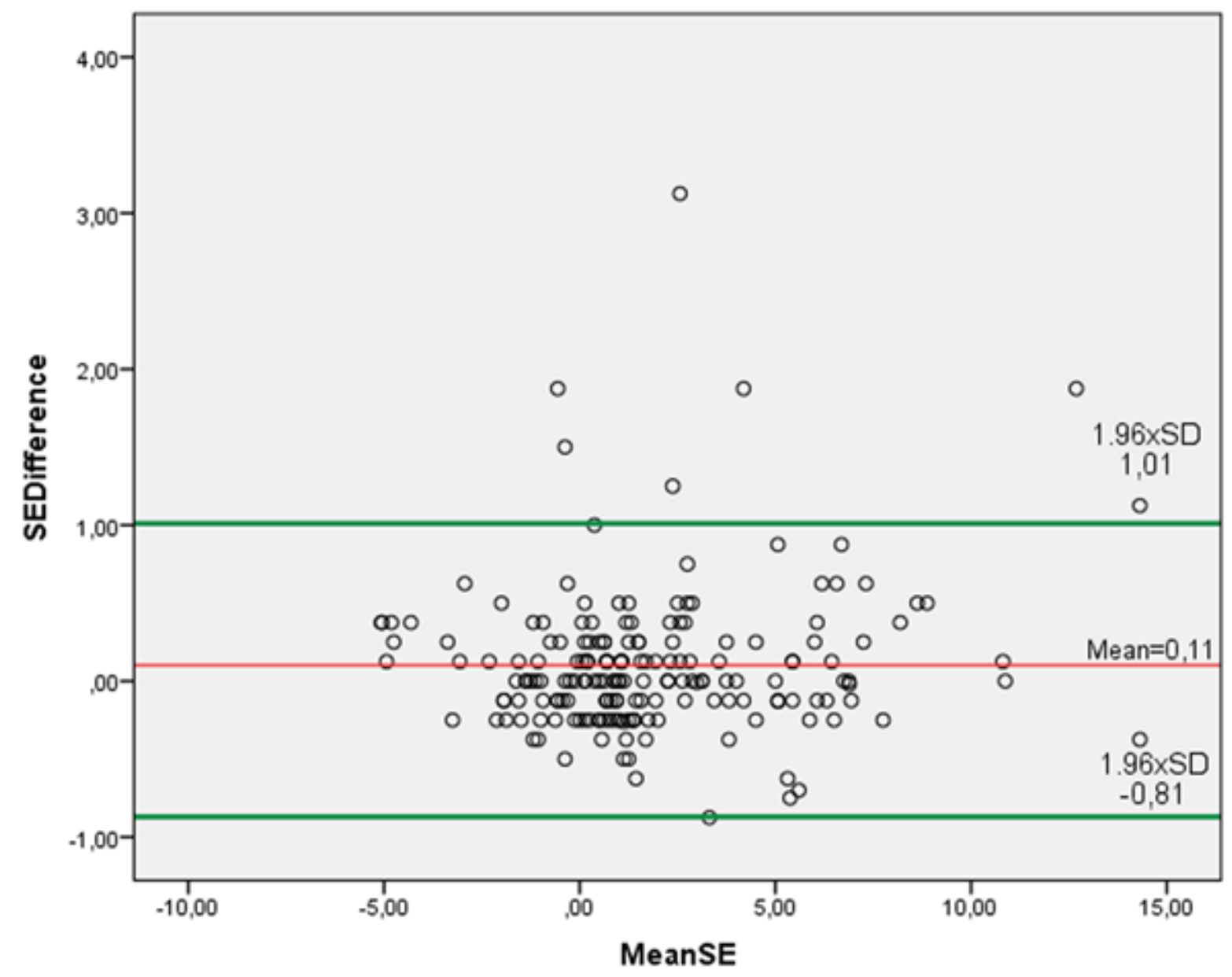

\section{Figure 4}

Bland Altman plot indicates the agreement between Topcon TRK-2P and Nidek HandyRef-K for the mean spherical equivalent. The middle line demonstrates the mean difference $(0.11 \mathrm{D} \pm 0.47 \mathrm{D})$, and the other two side lines show the $95 \%$ limits of agreement (-0.81 D to $1.01 \mathrm{D})$. 


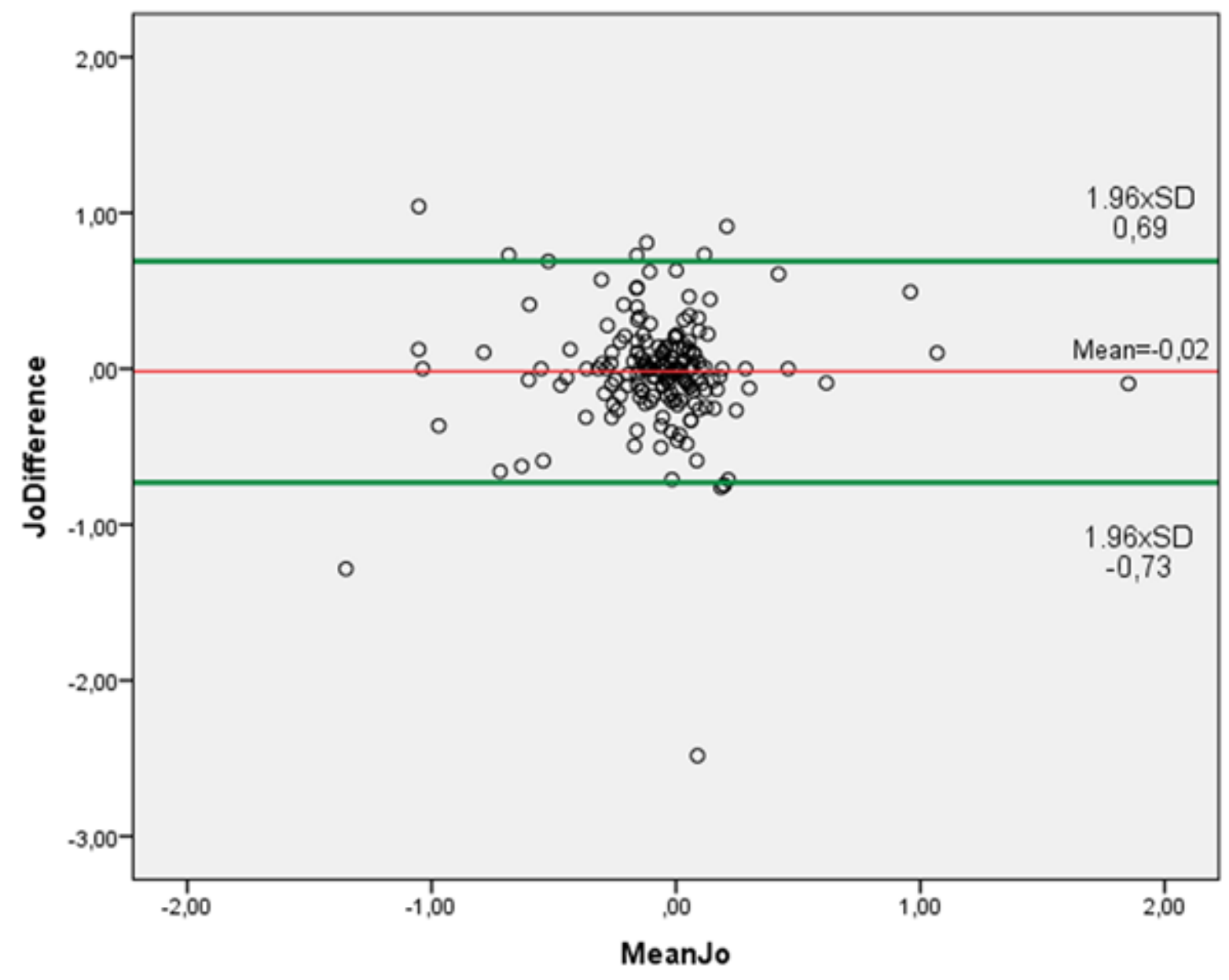

Figure 5

Bland Altman plot indicates the agreement between Topcon TRK-2P and Nidek HandyRef- $\mathrm{K}$ for the mean Jackson cross-cylinder power at $0^{\circ}$. The middle line demonstrates the mean difference (0.02 D $\left.\pm 0.36 \mathrm{D}\right)$, and the other two side lines show the $95 \%$ limits of agreement $(-0.73 \mathrm{D}$ to $0.69 \mathrm{D})$. 


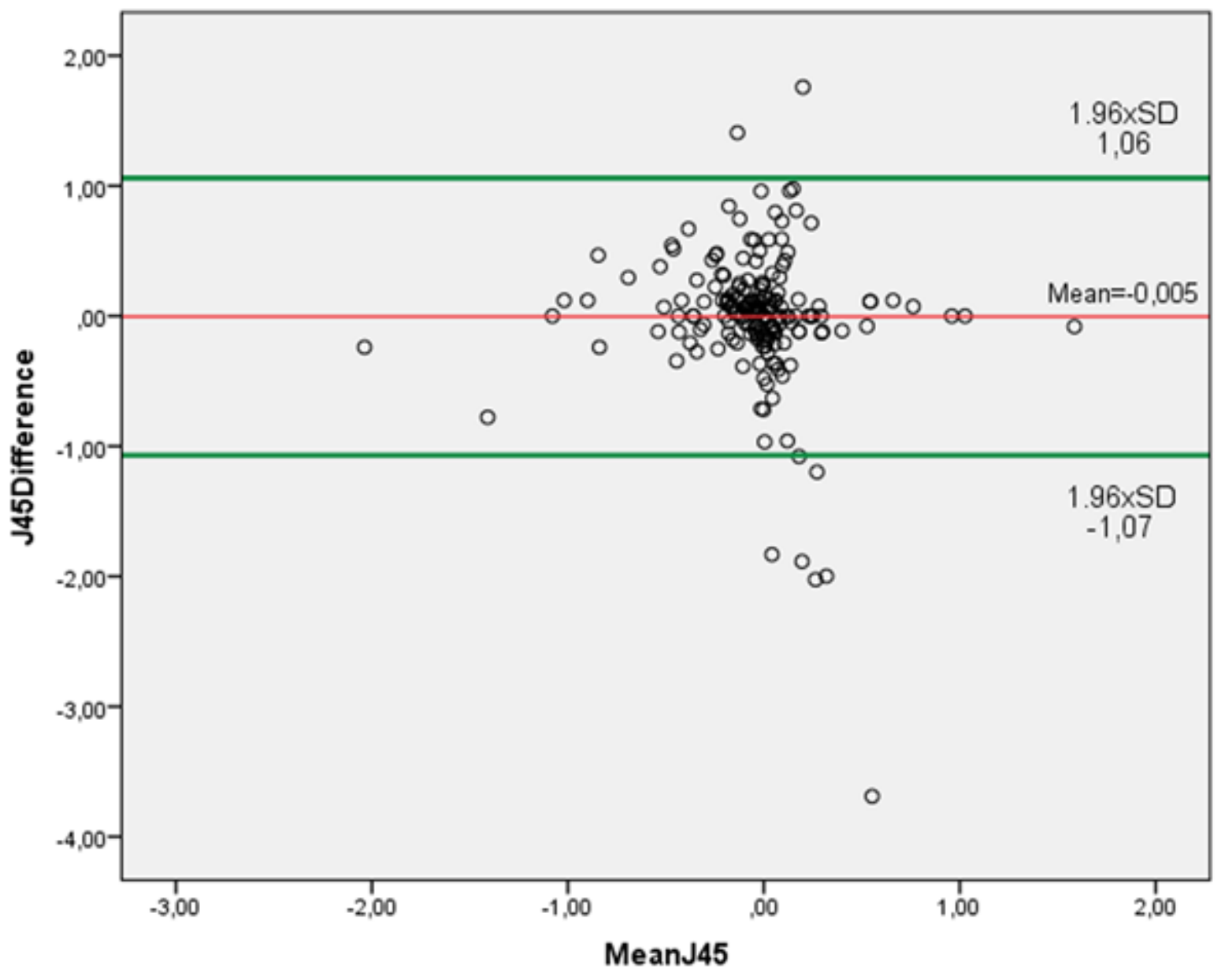

Figure 6

Bland Altman plot indicates the agreement between Topcon TRK-2P and Nidek HandyRef- $\mathrm{K}$ for the mean Jackson cross-cylinder power at $45^{\circ}$. The middle line demonstrates the mean difference $(0.005 \mathrm{D} \pm 0.54$ D), and the other two side lines show the $95 \%$ limits of (-1.07 D to $1.06 \mathrm{D})$. 